\title{
ASLI 2018

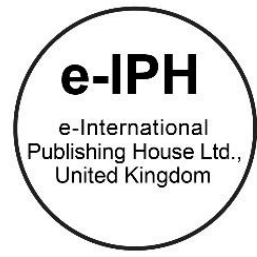 \\ Influence of Parental Feeding Attitude, Style and Environmental Factors on BMI among School Children
}

\author{
Roswati Nordin, Norimah Said, Fatin Faridah Nordin, Nurul Farhana Adnan \\ Centre of Nursing Studies, Faculty of Health Sciences, Faculty of Health Sciences, \\ Universiti Teknologi MARA Selangor, Puncak Alam Campus, \\ 42300 Bandar Puncak Alam, Selangor, Malaysia \\ roswati2809@puncakalam.uitm.edu.my,norimah2809@gmail.com, fatin92_nordin@yahoo.com.my,nurulfarhana_adnan@yahoo.com \\ $+6019-3725859$
}

\begin{abstract}
Obesity prevalence has drastically increased among Malaysian population of 31 million from 15.1\% in 2011 to $17.7 \%$ in 2015 . Many factors can leads to overweight and obesity among school children. The objective of this study is to examine the parental feeding attitude, style and environment factor influence on body mass index among overweight and obese school children. A cross-sectional study design was conducted. The result proved that majority of the overweight and obese children because of the negative attitude and poor practice by parents and poor environment surrounding them.
\end{abstract}

Keywords: Parental Feeding Attitude; Parental Feeding Style; Environment;

eISSN: 2398-4287@ 2018. The Authors. Published for AMER ABRA CE-Bs by e-International Publishing House, Ltd., UK. This is an open access article under the CC BYNC-ND license (http://creativecommons.org/licenses/by-nc-nd/4.0/). Peer-review under responsibility of AMER (Association of Malaysian Environment-Behaviour Researchers), ABRA (Association of Behavioural Researchers on Asians) and cE-Bs (Centre for Environment-Behaviour Studies), Faculty of Architecture, Planning \& Surveying, Universiti Teknologi MARA, Malaysia.

DOI: https://doi.org/10.21834/e-bpj.v3i7.1291

\subsection{Introduction}

Obesity prevalence in Malaysia shown drastically increase from 4.4\% in 1996 to $14 \%$ in 2006. The statistic shown an increasing number to $15.1 \%$ in 2011 to $17.7 \%$ in 2015 with the population of Malaysian is 3.1 million reported by National Health morbidity survey in 2015 (Ministry of Health, 2015). Obesity means situation where excess body fat has accumulated to the extent that health may be adversely affected. This excess body fat also have side effect on psychological well-being (WHO, 2004). Many factors can leads to overweight and obesity among school children such as secondary lifestyle, attitude, environment factor and more. Parental feeding attitude, style and environment factor can be the biggest causes that may influence child body mass index (BMI).

From the previous study, some researchers revealed that parental feeding practice play a critical role in the development of child taste preference, eating habits, nutrition, and eventual weight status. Research on behaviors mediators of familial patterns indicate that parent's behaviors influence the development of children's eating behaviors and there must be some other reason that contributes to the prevalence in childhood obesity either than genetic factor (Lent,M.R. 2017).

Other than that, a number of previous studies have identified when the parents had good practice on "healthy eating guidance and "monitoring" of their child dietary pattern, it will contribute to child weight status (Lent,M.R. 2017). Children that always take food from restaurant or fast food store can easily have overweight and obese BMI because these restaurants' food consumption in high calories (Powel, I. M., \& Nguyen, B. T. (2013). High intake in carbohydrate, fat and sugar but low intake in vitamin and mineral food can be the biggest factor of child overweight and obese in BMI (Shehu et al., 2010). Physical environmental can also one of the reason of obesity in life.

eISSN: 2398-4287@ 2018. The Authors. Published for AMER ABRA cE-Bs by e-International Publishing House, Ltd., UK. This is an open access article under the CC BYNC-ND license (http://creativecommons.org/licenses/by-nc-nd/4.01. Peer-review under responsibility of AMER (Association of Malaysian Environment-Behaviour Researchers), ABRA (Association of Behavioural Researchers on Asians) and cE-Bs (Centre for Environment-Behaviour Studies), Faculty of Architecture, Planning \& Surveying, Universiti Teknologi MARA, Malaysia.

DOI: https://doi.org/10.21834/e-bpj.v3i7.1291 
Previous study conducted by Maalouf (2011), stated that many factors can be the reason why children become overweight and obese such as attitude, lifestyle, environment factor and more. This factor comes from the children themselves or from the parent. Children like to eat something that is sweet and delicious. Children usually will eat what their parent eat or what the mother cook, so parental feeding attitude, style and environment factor such as family income, marital status of parent or number of family member can be the reason why children nowadays overweight and obese. Parental feeding attitude can be described as parent's behaviour during the children meals whether they are strict or not towards the children. Other than that, parental behavior also can be what parent eats that children may imitate (Scaglioni et al., 2008). Parent's behaviour can determine whether the child eat healthy food or not. Parental feeding style is parents' eating practice or how the parents usually eat at home. Parenting styles is parent practice during mealtimes including responsible and demanding of parental feeding (Blissett, 2011). Either parent eats healthy food or parent does not care about children eating (Cardel et al., 2012).

\subsection{Literature Review}

Many parents have self-belief that obesity is a congenital problem which causes the excess weight and do not consider how their own particular dietary patterns and the encompassing condition influence the child (Kelleher, Pallan, Lancashire, \& Adab, 2015). From the previous research showed, there must be some other reason that contributes to the prevalence in childhood obesity either than genetic factor. According to Johannsen et al. (2006), he investigated about effects of parents eating behaviors, child feeding practices and their own BMI versus their child's BMI and body fat percentage. The results showed that children more possibly to be overweight if their mother's believed that they had risky eating habits such as fussiness, overeating or under eating. Based on previous study in Chile of maternal attitudes, child feeding practices and child's weight status revealed that mother of overweight children were significantly more concerned about the child's weight and perceived their children as higher weight category while mother of normal weight children used significantly more pressure to eat (Mulder, 2009). It provides fundamental knowledge in the sustenance connection between the mother, child and food.

Besides, parent's attitude to children may contribute to healthy eating and ideal weight or can promote to overweight or aspects of disorder eating. Research on behaviors mediators of familial patterns indicate that parent's behaviours influence the development of children's eating behaviors (Scaglioni, Salvioni, \& Galimberti, 2008). Isabel Lin Tzou (2012) stated that mothers believed heavier infants and toddlers represented a predictor of good health and successful parenting. Because of fear, mothers introduces their children early with solid food before recommended to ensure their child get enough food to eat even they are aware that they were against nutritionals' advices. Introducing solid food at an early age is a belief from their mother's advice. At the point when little child with obese guardians ends up noticeably overweight, it is great marker of the kid forming heaviness as a grown-up.

Parenting style is a psychological construct representing standard strategies that parents use in their child rearing. The quality of parenting can be more essential than the quantity of time spent with the child (Hood et al., 2000). In psychology, there are four major recognized parenting styles which are indulgent parenting, authoritative parenting, authoritarian parenting and uninvolved parenting (Shloim, Edelson, Martin, \& Hetherington, 2015). Each one carries different characteristics and brings about different reactions in the children which they are used to. It is vital to remember that every parent child relationship is distinctive, so there is not one beyond any doubt fire approach to child rearing. This is a simple guide to help decode your parenting style and provide general suggestions on how to raise a happy, responsible, productive member of society.

Authoritative parenting is widely regarded as the best and valuable child upbringing style for ordinary children (Shloim et al., 2015). Authoritative parents are easy to recognize, as they have high expectations on their children, but lower these expectations with understanding can support their children. This type of parenting creates the healthiest environment for a growing child, and helps to foster a productive relationship between parent and child. Feeding styles might be seen as a sub class of child upbringing styles that are particular to mealtimes and along these lines similar measurements of demandingness and responsiveness are connected in the nourishing setting (Hughes, 2005). So, with an authoritative feeding style, parents 10 actively reassure their child to eat but achieve this through supportive behaviours while authoritarian feeding style, parent encourage eating through parent-centric rules (Johnson et al., 2012).

Parent's child feeding practices are associated with children's eating behaviors, including specific eating styles, food selection and preferences, and the regulation of energy intake (Kral \& Faith, 2009). Food preferences develop from genetically determined predisposition to like sweet and salty flavors and to dislike bitter and sour tastes. There is a confirmation for the presence of some intrinsic, automatic mechanism that regular appetite. In one to three years infant energy intake regulation is effective if there is a wide offer of plain foods. With plain foods, children choose their diet without instruction from the adults.

Parental control describes in two which are restriction and pressure. For restriction of pleasant foods and pressure to eat, parental feeding practices predominantly have related to children's body mass index and energy consumptions (Cardel et al., 2012). Parental restriction has been definitely related with child body mass index (BMI), overeating, and weight gain. It has been theorized that parental restriction may limit a child's ability to self-regulate energy intake and focus on children's attention on restricted foods, which may lead to overconsumption when the restricted foods become freely available (Brown \& Ogden, 2004). Restriction involves restricting children's access to junk food and the restricting the total amount of food.

Environment factor that can influence obesity of the children would be from many aspects for example socio-demographic characteristic such as parental education level, marital status of parent's, family income and the number of family members. Other than that, demographic location also can influence obesity in children. Individuals who live (Rundle et al., 2009) or shop (Morland et al., 2006) in the areas that have more healthy food stored such as supermarket can influence the consumption of fruits and vegetables among its 
minority residents (Morland et al., 2006). What researcher can understand here is if children stay or live at area that have healthy food stored such supermarket, then that child may have better BMI because they may have taken healthy food at home with food pyramid guideline. Parental educational level can be one of the factors that may influence child overweight or obese. Parent that have high education level must know about normal BMI and have knowledge on healthy food for children and vice versa for parent that have low education level. So that, parent can control rates of child overweight (Variyam, 2001).

\subsection{Methodology}

The cross-sectional study design was used and descriptive techniques were carried out at Sekolah Kebangsaan Damansara Damai 2. The respondent included parents of standard 4 and 5 school children with overweight and obese BMl. Other than that, respondent were chosen based on inclusion and exclusion criteria. Children with severe disabilities who's on medication that might affect body composition and active as athletes who categorize in overweight and obese was the exclusion criteria that researcher list down.

Population of students from SK Damansara Damai 2 is $\mathrm{N}=250$ for standard 4 to 6 . Using Raosoft software, the minimal sample size was $(n=152)$. Confidence interval is $5 \%$ and the confidence level is $95 \%$ with $5 \%$ margin error. With cluster sampling, the researcher divides about 152 students into separate groups. The cluster may involve group of underweight, normal, overweight and obese body mass index (BMI) selected from the population. After considered based on overweight and obese BMI with excluded standard 6 students, the researcher got 44 students to be a sample in this study.

Self-administered questionnaire were used to determine the parental feeding, style and environment factor influence of BMI among overweight and obese school children. The questionnaire includes the Comprehensive Feeding Practices Questionnaire (CFPQ) adopted from Musher- Eizenman in 2007 (Musher, 2007). The original English versions CFPQ was translated into Malay by our research group and have been verified with English teacher. The validity of questionnaire was examined through test- retest and Cronbach's alpha methods. The Intraclass Correlation Coefficient (ICC) was between 0.80 to 0.91 and Cronbach's alpha between 0.80 to 0.90 .

Each parental feeding attitude, style and environment items was on 5 point likert scale, ranging from 'strongly disagree to strongly agree' and from 'never to always'. For calculating the score, the score had been recorded to 3 point-scale. Zero point given to responses 'strongly disagree', 'disagree', 'never' and 'rarely'. One point is given to responses for 'sometimes' and 'neutral' while two points given to all responses for 'agree', 'strongly agree', 'mostly' and 'always'. The respective maximum score for attitude and practice were 40 while for environment was 18. The individual score was then summed up to yield a total score. Maximum score for attitude, style and environment considered as positive attitude, good practice and healthy environment (Lent, 2017).

Screening of the students had been done by physical education teacher. All the weight and height of the students recorded to calculate their body mass index (BMI). The names of the students who reached overweight and obese BMI had been listed and given to the researcher. One slot of program had arranged by the teacher for the researcher to distribute the questionnaire. The researcher would approach the selected students who fulfilled the inclusion criteria and the purposes of the study are explained verbally. The respondents would receive the questionnaire through their children as the children will bring the envelope home. In the envelope there are instructions to complete the questionnaire and the consent form. Upon completion, the respondents were provided with selfaddressed envelope to seal their questionnaire in and return it to their children. The children would give back the envelope to the in charge teacher and the researcher would collect it. All the data would be collected after the respondents complete the questionnaire.

Ethical issues that are considered in this study are the permission of this research to be carried out in the Sekolah Kebangsaan Damansara Damai 2 which obtained from Ministry of Education and followed by permission from District Education office of Selangor. Other than that, respondents' personnel data will be kept confidentially. All data would be collected and would be used only for the purpose of the study and would not be passed to anyone else.

\subsection{Result s}

\subsection{Association parental feeding factor with BMI}

Table 1. Parental feeding attitude according to overweight and obese child BMI

\begin{tabular}{lcc} 
& \multicolumn{2}{c}{ Attitude } \\
\cline { 2 - 3 } Overweight & Positif & Negative \\
Obese & 2 & 4 \\
& 16 & 22 \\
\hline
\end{tabular}

Table 2. Parental feeding style according to overweight and obese child BMI

\begin{tabular}{lcc} 
& \multicolumn{3}{c}{ Style } \\
\cline { 2 - 3 } Overweight & Good & Poor \\
Obese & 2 & 4 \\
\hline
\end{tabular}


Table 3. Environment factor according to overweight and obese child BMI

\begin{tabular}{lcc} 
& \multicolumn{2}{c}{ Environment } \\
\cline { 2 - 3 } Overweight & Healthy & Poor \\
Obese & 2 & 4 \\
& 16 & 22 \\
\hline
\end{tabular}

Refer to table 1 , there were $n=44$ respondent in this study that were parent of student with overweight and obese BMI. There were only $n=6$ respondents were having child with overweight BMI. Other $n=38$ were respondent that have child with obese BMI. For overweight student, only $n=2$ respondent that took a positive parental feeding attitude while another $n=4$ took negative parental feeding attitude. And for obese student, there were $n=16$ parent that took positive parental feeding attitude and another $n=22$ parent that took negative parental feeding attitude.

Refer to table 2, for respondent with good parental style there were only $n=16$ respondent and another $n=28$ respondent practice poor parental feeding style. In $n=16$ respondent practice with good parental feeding style, there were only $n=2$ respondent that have overweight child BMI and another $n=14$ respondent have child with obese BMI. For respondent with poor parental feeding style, there were $n=4$ respondent that have child with overweight $B M I$ and $n=24$ respondent have child with obese BMI.

Refer to table 3, respondent that have overweight child $n=2$ stay in healthy environment while another $n=4$ respondent stay in poor environment. For respondent that have child with obese BMI, there were $n=16$ respondent that stay in healthy environment while another $\mathrm{n}=22$ respondent stay in poor environment.

\subsection{The most prediction factor influence BMI}

Table 4 : The most prediction factor that influence on BMI

\begin{tabular}{lcccc}
\hline Variable & \multicolumn{4}{c}{ BMl } \\
\hline Parental feeding attitude & $\mathrm{b}$ & $95 \%, \mathrm{Cl}$ & F.stat (df) & P-value \\
& -2.9 & $(-5.30,-0.49)$ & $5.903(1,42)$ & 0.019 \\
\hline R2 $=0.123$ the model reasonably fit well: Model assumptions are met
\end{tabular}

$\mathrm{R} 2=0.123$ the model reasonably fit well: Model assumptions are met

Refer to table 4, there was a significant linear relationship between attitude and $B M I(P=0.039)$. This result explained 10 per cent of the variability in $\mathrm{BMI}, \mathrm{F}(1,42)=5.90, \mathrm{p}<0.05$. An examination of Mahalanobis distance value indicates that there are no multivariable outliers among independent variable: that is, no values are greater than or equal to the critical chi-square value of 13.8 at an alpha level of 0.001 .

\subsection{Correlation between demographic data with parental feeding factor}

Table 5. Correlation between demographic data (marital status, income, education level and occupational) with parental feeding attitude

\begin{tabular}{lcc}
\hline \multicolumn{1}{c}{ Variable } & Pearson's correlation, $r$ & $p$-value \\
\hline Marital status & 0.107 & 0.244 \\
Income & $0.295^{*}$ & 0.026 \\
Education level & 0.201 & 0.095 \\
Occupational & -0.080 & 0.303 \\
\hline
\end{tabular}

Table 6. Correlation between demographic data (marital status, income, education level and occupational) with parental feeding environment

\begin{tabular}{lcc}
\hline \multicolumn{1}{c}{ Variable } & Pearson's correlation, $r$ & p-value \\
\hline Marital status & 0.048 & 0.379 \\
Income & $0.293^{*}$ & 0.027 \\
Education level & 0.121 & 0.216 \\
Occupational & -0.128 & 0.204 \\
\hline \multicolumn{3}{c}{}
\end{tabular}

Table 5 shows that income had positive significant correlation with parental feeding attitude $(r=0.295)(p=0.026)$ while marital status, education level and employment did not show any significant correlation with this factor. Table 6 shows that income had positive significant correlation with parental feeding environment $(r=0.293)(p=0.027)$. However, there was no correlation between marital status, education and occupational with parental feeding environment.

\subsection{Discussions}

For parental feeding attitude factor, there were positive and negative parental feeding attitude. Respondents have positive parental feeding attitude $n=18$ and respondents with negative parental feeding attitude $n=26$. Positive or negative parental feeding attitude may determine children BMI. Parental feeding attitude was parental feeding behaviour during taking meal either positive or negative will give effect to children BMI (Scaglioni et al., 2008). The result showed there were many respondents that compliance with negative parental feeding attitude have child with abnormal BMI. This due to negative parental feeding behaviour gives negative effect to children 
behaviour during eating that can influence their BMI (Scaglioni et al., 2008). Children tend to eat unhealthy food such as snack and fast food (Musher-Eizenman \& Holub, 2007). So as a parent, they should present positive parental feeding attitude to child such as parent should strict during choosing meal to eat and only pick healthy food.

Respondents practice poor parental feeding style $n=28$ and the other respondents practice good parental feeding style $n=16$. Respondent that practice poor parental feeding style does not monitor their child eating unhealthy food. They just let their child eating snacks and sweets whenever their child wants to eat. Increasing in calories occurs when children eat lot of snack and sweet (Piernas \& Popkin, 2010). Other than that, respondent need to encourage balance and variety of food during eating to child, respondent also need to restrict unhealthy food for child health, and respondent must be the role model to the child for them to eat healthy food. These factors have been concluding under style by Musher-Eizenman \& Holub (2007).

26 respondents that stay at poor environment and 18 respondents stay at healthy environment. Healthy environment is living area that respondent stay was area that has market and respondent easily get healthy food there while poor environment is where the respondent stay at area that near to fast food store (Oreskovic, Kuhlthau, Romm, \& Perrin, 2009). This healthy and poor environment divide based on the questionnaire that have been compile under factors healthy environment that are from question 14,16, 22 and 37. Other than that, factor involvement also can be concluding under environment factor. Plus, respondent need to keep healthy food at home to prevent child from getting unhealthy food. Child may get unhealthy food outside home that is why they need to eat healthy food at home.

The most prediction factor that influence BMI was parental feeding attitude based on significant value $p<0.05$. Parental feeding attitude is how respondent behaviour while their children eat. Most of the previous researches also state that parental feeding attitude is significant with overweight and obese BMI of children (Francis \& Birch, 2005). Other than that, family pattern of eating can be indicated by parent's behaviour. Thus, parental feeding attitude may influence children eating behaviour (8). In addition, parent that always restrict their child eating and restrict about child weight will end up with increasing of child BMI (Fisher, Sinton, \& Birch, 2009). This is because child feel emotional eating and feel awkward to eat a lot of food if their parent there. Restriction of weight control is under parental feeding attitude. If parent too strict about child weight then, child will get stress and end up eating lot of food to reduce stress. Stress can promote irregular eating and overeating then can increasing BMI (Yau \& Potenza, 2013).

According to the result, the income of the respondent has correlation with the parental feeding attitude and parental feeding environment $(p<0.05)$ even though the strength of relationship were weak. According to demographic data, most of the respondents earned lower income per month. Parental feeding attitude of low income parents were related to what children actually ate. The statement was supported with present study by Hoerr et al, (2009) that found parental feeding attitude and children food's intake in families associate with limited income ( Hoerr et al, 2009). Normally parents with limited income try to train their children to eat certain food according to their ability. Sometimes low nutrition food given as long as the food was affordable for them. According to research by Spurrier et al, (2008), parental restriction regarding dietary pattern of children associate with poorer ones. In conclusion, parent's income will affect parent's attitude as well as toward dietary pattern of their children (Lovelace \& Rabiee-Khan, 2015). For parental feeding environment (involvement and healthy environment), parents create environment for children that may foster the development of healthy eating behavior and weight or that may promote overweight and aspects of disordered eating. Based on present study, parents noticed that children ate wider variety of food outside the home and it would influence the children's diet and also weight (Lovelace \& RabieeKhan, 2015). Fast food consumption is associated with a diet high in calories and low in nutrients, and frequent consumption may lead to weight gain (Powell \& Nguyen, 2013).

\subsection{Conclusion}

This study shows about the prevalence of obesity among children and the related of parental feeding attitude, practices and environment effected on children's BMI. It is important for parents to understand this study in order to ensure their children having better life with ideal body mass index. It also will help to reduce obesity among children in Malaysia. From this study also, the researcher is targeting to prove the most affected factors either parental attitude, style or environment influence children body mass index (BMI). So, some improvement can be made after getting the result of this study. Besides that, a lot of previous studies had been mentioned in this research that proved parental feeding attitude, style and environment factors had relationship with weight status of school children. Besides that, parents can also take a class or counselling about nutrition or healthy eating pattern. It is important for parents to understand this study in order to ensure their children having better life with ideal body mass index. According to the result, the researchers concluded that majority of the overweight and obese children because of the negative attitude and poor practice by parents and unhealthy environment surrounding them. Moreover, parental feeding attitude resulting as the best prediction factor influence on body mass index among obese and overweight children and lastly the researchers suggested that there were correlation between demographic data (income of parents) with parental feeding attitude and parental feeding environment.

\section{Acknowledgements}

Special thanks to Ministry of Education, Selangor State Education, UiTM Research Ethic Committee, Parents of student Sek Keb Damansara Damai 2 and Grant Lestary008/2016. 


\section{References}

Benton, D. (2004). Role of parents in the determination of the food preferences of children and the development of obesity. International Journal of Obesity, $28,858-869$.

Hoerr, S. L., Hughes, S. O., Fisher, J. O., Nicklas, T. A., Liu, Y., \& Shewchuk, R. M. (2009). Associations among parental feeding styles and children's food intake in families with limited incomes. International Journal of Behavioral Nutrition and Physical Activity, 6(1), 55. https://doi.org/10.1186/1479-5868-6-55

Institute for Public Health. (2015). National Health and Morbidity Survey 2015 (NHMS 2015). Vol. II: Non Communicable Diseases, Risk Factors \& Other Health Problems. Ministry of health (Vol. II). http://doi.org/10.1017/CBO9781107415324.004

Johannsen, D. L., Johannsen, N. M., \& Specker, B. L. (2006). Social and Behavioral Influence of Parents' Eating Behaviors and Child Feeding Practices on Children's Weight Status. Obesity Research Journal, Vol.14 (No.3), 430-437.

L.A.Francis and L.L.Birch. (2005)."Maternal weight status modulates the effects of restriction on daughters eating and weight," International Journal of Obesity, vol.29, 942-949.

Lent, M. R. (2017). Parental Feeding Practices among Brazilian School Aged Children: Associations with Parent and Child Characteristics, 4(March), 1-10. https://doi.org/10.3389/fnut.2017.0000 6

Lovelace, S., \& Rabiee-Khan, F. (2015). Food choices made by low-income households when feeding their preschool children: A qualitative study. Maternal and Child Nutrition, 11(4), 870-881. https://doi.org/10.1111/mcn.12028

Musher-Eizenman, D., \& Holub, S. (2007). Comprehensive feeding practices questionnaire: Validation of a new measure of parental feeding practices. Journal of Pediatric Psychology, 32(8), 960-972. http://doi.org/10.1093/jpepsy/jsm037

Pai, H. L., \& Contento, I. (2014). Parental perceptions, feeding practices, feeding styles, and level of acculturation of Chinese Americans in relation to their school-age child's weight status. Appetite, 80, 174-182. https://doi.org/10.1016/j.appet.2014.04. 029

Piernas, C., \& Popkin, B.M. (2010). Trends in snacking among US children. Health Affairs,

Powel, L. M., \& Nguyen, B. T. (2013). Fast-food and full-service restaurant consumption among children and adolescents: effect on energy, beverage, and nutrient intake. JAMA Pediatrics, 167(1), 14-20. https://doi.org/10.1001/jamapediatrics. 2013.417

Rodgers, R. F., Paxton, S. J., Massey, R., Campbell, K. J., Wertheim, E. H., Skouteris, H., et al(2013). Maternal feeding practices predict weight gain and obesogenic eating behaviors in young children: a prospective study. International Journal of Behavioral Nutrition and Physical Activity, 10, 24. http://dx.doi.org/10.1186/1479-58681024.

Scaglioni, S., Salvioni, M., \& Galimberti, C. (2008). Influence of parental attitudes in the development of children eating behaviour. British Journal of Nutrition, 29(SUPPL.1), S22-S25. https://doi.org/10.1017/S00071145088 92471

Shehu, R.A., S.A. Onasanya, T.A. Oloyede and M. Kinta. (2010). Contribution of information and communication technology to the prevalence of obesity and elevated blood pressure among secondary students in Nigeria. J. applied Sci., 10: 359-362

Spurrier, N. J., Magarey, A. A., Golley, R., Curnow, F., \& Sawyer, M. G. (2008). Relationships between the home environment and physical activity and dietary patterns of preschool children: a cross-sectional study. International Journal of Behavioral Nutrition and Physical Activity, 5(1), 31. https://doi.org/10.1186/1479-5868-5-31

Thornton, L. E., \& Kavanagh, A. M. (2012). Association between fast food purchasing and the local food environment. Nutrition and Diabetes, 2 (12), e53. http://doi.org/10.1038/nutd.2012.27

World Health Organisation (WHO) Expert Consultation.(2004). Appropriate Body Mass Index for Asian Populations and its Implications for Policy and Intervention Strategies. Lancet, 363:157-63

Yau, Y. H. C., \& Potenza, M. N. (2013). Stress and eating behaviors. Minerva Endocrinologica, 38(3), 255-267. http://doi.org/10.3410/B2-13 Bishop, K., \& Said, I., (2017). Challenges of Participatory Qualitative Research in a Malaysian and Australian Hospital. Asian Journal of Environment-Behaviour Studies, 2(4), 1-11. 